\title{
A Test of Return Predictability in the Vietnamese Stock Market
}

\author{
Thanh Trung Le ${ }^{1} \&$ Anh Tram Luong ${ }^{1}$ \\ ${ }^{1}$ University of Economics and Business, Vietnam National University, Hanoi, Vietnam \\ Correspondence: Thanh Trung Le, University of Economics and Business, Vietnam National University, Hanoi, \\ Vietnam.
}

Received: December 21, 2019

Accepted: February 3, 2020

Online Published: March 24, 2020

doi:10.5430/ijfr.v11n2p390

URL: https://doi.org/10.5430/ijfr.v11n2p390

\begin{abstract}
For the first time, the market efficiency is examined in the different context of the stock market. By employing tests of weak-form efficiency, this study finds out that the overall, Vietnamese stock market does not follow a random walk regardless of the degree of stock market volatility. Therefore, technical analysis could be used by investors and financial managers to forecast price and gain profits on the market. Another finding is that although the Vietnamese market is not weak-form efficient, there is an improvement in recent years. The paper suggests that if investors and financial managers can employ past returns to predict stock prices and make decisions on the Vietnamese market, they should change their strategies in the future. This finding also contributes to studies on the Efficient Market Hypothesis in emerging countries and its performance in different economic contexts.
\end{abstract}

Keywords: the efficient market hypothesis, stock volatility, the Vietnamese stock market

\section{Introduction}

The Efficient Market Hypothesis (EMH) concerns about the relationship between information and security prices, which influences the process of predicting future prices. To be more precise, the EMH determines whether security prices can be forecasted by different types of information or not. This theory is important for both investors and financial managers. While investors attempt to forecast stock prices to make investment decisions and gain profits, financial managers predict stock prices to design business strategies and maximise shareholder value.

Fama (1965) introduced the concept of the EMH for the first time with the random walk theory of stock price behaviour. He made two assumptions underlying the market efficiency: (1) independent successive price changes, (2) the probability distribution of price changes. These assumptions make the price to be an independent random variable because it is the result of new information; and the process of generating new information makes the price changes be unpredicted (Fama, 1965). Then, after researching the actions of "sophisticated traders", Fama (1970) developed the random walk theory to the EMH. In this case, all sophisticated traders attempt to trade to gain above-average returns, leading to the fact that anomalies are widely acquired by rational investors. Malkiel (2003) approved this theory, he said that when all investors tends to trade to earn this excess returns, anomalies are eliminated and the market will become increasingly efficient.

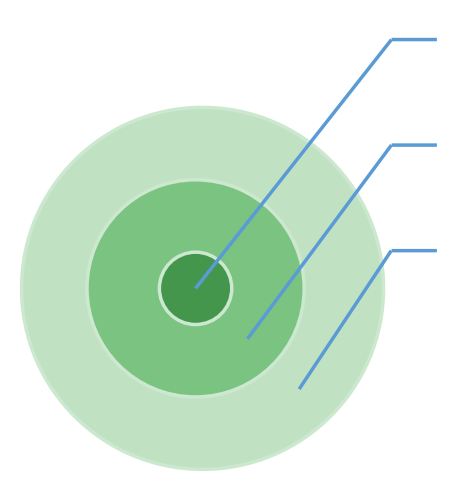

Figure 1. Three levels of conformity to an efficient market

\author{
Strong-form \\ efficiency \\ Semi-strong form efficiency \\ Weak-form \\ efficiency
}


Figure 1 shows that there are three levels of market efficiency: weak-form efficiency, semi-strong form efficiency and strong-forms efficiency (Fama, 1970)

In the weak-form of efficiency, current and future securities prices cannot be forecasted by employing the basis of past prices only (Fama, 1970). Technical analysis is disabled in this form because all the past information, which is fully reflected in stock prices, is accessed by many financial managers. Hence, security prices are immediately adjusted to the equilibrium point. In other words, financial managers cannot use the trend analysis of past prices to make predictions and make investment decision. However, there is possibility that managers can use other public information such as GDP, the policy of the government and the financial statements to determine the current value and future growth of the targeted company or to 'time' the issue of securities. In the semi-strong efficiency, all public information is reflected in the prices, so both technical analysis and fundamental analysis is disabled. However, there is still the potential for yield above average in the short term if some investors can obtain private information before the others. In the strong-form efficiency, investors and financial managers cannot employ any techniques in order to measure the stock prices because all information is immediately reflected in the prices. The stock prices in strong-form efficiency is known as 'fundamental value', which is the core value of the security. Thus, investors and financial managers has no possibility to beat the market.

Fama (1970) stated three levels of market efficiency consistent with three test categories: weak-form tests (How to use past returns to forecast the future returns?), semi-strong-form tests (How quickly is publish information reflected in market prices?) and strong-form tests (Is private information fully reflected in security prices?). However, Fama (1991) reviewed the theoretical and empirical literatures on EMH, clarified the three categories and named as tests for return predictability, tests for event studies and tests for private information.

The degrees of the conformity to the market efficiency is different over the world, especially between emerging and developed markets. To provide comprehensive understandings on the weak-form efficiency (or the return predictability) in the emerging markets, this paper uses empirical evidences from the Vietnamese stock market with different degrees of stock market volatility. There are several reasons for conducting this research.

Firstly, there is a range of studies on the EMH in the emerging markets. For example, researches are carried out by Buguk and Brorsen (2003) in Istanbul, Chaudhuri and Wu (2003) in 17 developing countries and Claessens, Dasgupta and Glen in 19 countries. However, these researches mainly focuses on countries in South America and South Asia. Regarding to Southeast Asian countries, Thailand and Philippines are the two popular countries in examination. Unfortunately, the Vietnamese stock market is still new to researchers. Therefore, there are insufficient studies on the EMH in the Vietnamese market.

Secondly, it is essential to consider the EMH in different levels of stock volatility because the stock prices may behave differently in different market contexts. The Vietnamese stock market has 19-year history with many turning points. In each period, the volatility of stock prices was different, leading to the concerns that the ability to predict future prices based on past returns can be different. However, there is no previous study on this issue.

Lastly, the EMH can change throughout time due to changes in politic, economic and technical environment. However, there is lack of studies concentrating on the improvement in the efficiency of the Vietnamese stock market throughout the time. Most of previous studies examine this market during a long unstable period and test several effects such as monument effect, day-of-week effect and January effect. The researchers include Loc (2006), Guidi (2011), Do, Le and Nguyen (2012), Alphonse and Nguyen (2013) Phan and Zhou (2014), and Swint (2015). Only study by Phan and Zhou (2014) examined weekly data of the market index and claimed the improvement in efficiency in 2010. Therefore, it is necessary to do further studies on the market to gain clear understandings on the EMH.

There are many economic literatures on test for return predictability. The forecast power of past returns is practical examined by a range of previous studies on both short-horizon and long-horizon returns. Regarding to the short-horizon returns, early studies by Fama (1965), Fisher (1966), Lo and MacKinlay (1988) and Fama (1991) suggest the evidences of time-series predictability. For instance, by adopting the autocorrelation test on weekly returns, Lo and MacKinlay (1988) found out the positive serial correlation in the average price of portfolios on the New York Stock Exchange. Moreover, Fisher (1966) emphasised that the auto-correlation of diversified portfolios is stronger than individual stocks. The more recent evidences of the auto-correlations of daily, weekly and monthly returns are mentioned in the next part of this chapter. In terms of the return predictability of long-horizon returns, Fama (1991) suggested that the Shiller-Summers model could be employed to find out the relationship among successive returns. However, there are many empirical studies providing arguments for the random walk hypothesis, providing controversy about the return predictability. In particular, a large number of recent researches on stock 
markets such as the United Kingdom, Canada and European countries reject the forecast power of past returns. For example, researchers are Narayan and Smyth (2006) Alexeev and Tapon (2011) and Konak and Seker (2014).

Findings from this paper will contribute to the literatures on the EMH in emerging countries in general and in Vietnam in particular. Furthermore, by updating data until June 2019, the paper will show the changes in the market efficiency throughout 19-year operation. This allows the study to provide comprehensive understandings and empirical evidences on this hypothesis. Finally, there is no previous studies on the EMH in the Vietnamese stock market, which has different levels of stock volatility. This paper uses the standard deviation of the VN-Index to split the time and analyses the random walk hypothesis on four sub-samples. This view can provide a foundation for future researches to examine the EMH and the random walk hypothesis based on the stock volatility.

This paper is structured as following: The first section is the Introduction, reflecting general understandings about research problems, research aims and the contribution of this study. The next section represents the background of this study. The third section explains the selection of data collection and data analysis. The results from four tests on the return predictability of the Vietnamese stock market is presented in the fourth section. The last section summaries the findings of this paper and gives recommendations for investors and financial managers in Vietnam.

\section{The Background of the Study}

The financial system in Vietnam started to be developed from the Doi Moi economic reform in 1986. Together with the banking system, the stock market plays important roles in allocating funds and supporting the liquidity of the economy. The first stock exchange was launched in 2000 and known as Ho Chi Minh City Stock Exchange (HOSE). This is the biggest stock exchange in Vietnam. The Vietnam Stock Index (VN-Index) is the capitalization-weighted index of all the companies listed on the HOSE. After 19 years of operation, the Vietnamese stock market has experienced a dramatic development in both volume and quality. As can be seen from Figure 2, the trading volume per day on the Vietnamese stock market increased rapidly from 4.2 million USD in July, 2000 to about 120 billion in June, 2019 (Vndirect, 2019).

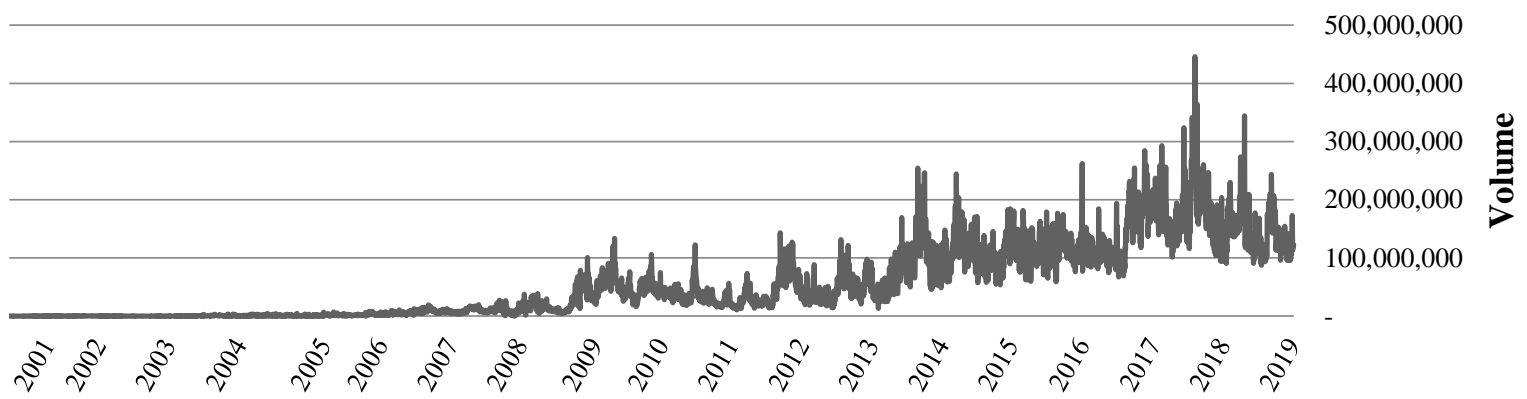

Figure 2. Daily trading volume of the VN-Index

The stock market has important roles in providing investment opportunities for investors, hedge fund managers, domestic and international firms. However, there are several concerns about issues that make the Vietnamese stock market inefficient. Firstly, since Vietnamese stock market is at early stage of development, rules and regulations have potential to have some flaws and do not meet international standards (World Bank, 2016). The second drawback of the Vietnamese stock market is the lack of transparency; it shakes the confidence of investors (Vo, Nguyen and Pham, 2016). Foreign firms investing in Vietnam may confront with the lack of information due to the weak accounting system and information management. For example, almost all of European countries and Americas use the Third Basel Accord as regulatory framework in accounting and financial management; however, the Second Basel Accord has been applied in Vietnam since 2014 (The Vietnamese government, 2017). This standard is newest accounting standard in Vietnam; so many companies have still found difficulty in meeting this regulation. Finally, according to World Bank (2016), the financial system in Vietnam lacks incentives for companies to raise capital from the security market; therefore, there is no motivation for investors and financial managers to acquire information to trade on the stock market.

The importance of understandings on the EMH and the drawbacks of the Vietnamese stock market motivate us to examine the return predictability in this market. 


\section{Data Sources and Methodology}

\subsection{Data Sources}

For the aims of this study, the daily return of VN-Index is collected from $28^{\text {th }}$ July 2000 to $28^{\text {th }}$ June 2019 obtained from Vndirect Securities Corporation's website. Since in the early period of the market, the stock exchange only opened on Monday, Wednesday and Friday, the sample size for the full period is 4556.

The validity and reliability of secondary data refers to the suitability of data and the reputation of data sources (Saunders et al, 2015). In terms of measurement validity, data collected in this research is daily VN-Index from the 19-year period of operation of Vietnamese stock market. Therefore, the data is relevant and suitable for the purpose of this study. In terms of reliability, the assessment is based on the organization providing data and the data collection technique (Saunders et al, 2015). The data studied was collected from Vndirect Securities Corporation's website. Vndirect founded in 2006 is a reputable financial corporation in Vietnam. They provide standardised information about all companies listed on HOSE. Vndirect is in the Top 4 companies holding the largest market share in HOSE (Vndirect, 2019). The information on the Vndirect's website is updated daily from companies' financial reports. Furthermore, regarding to the reliability of results, the data was collected during approximately 19-year period with the sample size is 4556 . Thus, the number of observations is sufficient to make statistical analysis such as doing regression and undertaking statistical tests. The Eview software is employed for statistical analysis.

\subsection{Data Analysis Method}

This study employs four tests including Unit root test, Autocorrelation test, Run test and Variance Ratio test to evaluate the return predictability on the Vietnamese stock market.

In this study, a natural logarithm transformation is applied to the primary data to create a time series of continuously compounded rate. The returns are computed as following:

$$
r_{t}=\log \left(\frac{P_{t}}{P_{t-1}}\right)
$$

where $r_{t}$ is the returns at time $t, P_{t}$ is the price at time $t$ and $P_{t-1}$ is the price at time $t-1$

\subsubsection{Unit Root Test}

In terms of the EMH, the random walk hypothesis claims that that the future prices cannot be predicted from the past prices and several other variables. Therefore, the prices in the weak-form efficiency should be consistent with nonstationary data. The model investigated is as following:

$$
\Delta X_{t}=\mu+\beta t+\delta X_{t-1}+\sum_{i=1}^{N} \varphi_{i} \Delta X_{t-i}+e_{i}
$$

where $\mu, \beta, \sigma$, and $\varphi$ are parameters, $e_{i}$ is white-noise innovation; $t=1,2 \ldots ; X_{t}$ is stock returns; $\mathrm{N}$ is the lag truncation order of the autoregressive process.

The use of the regression (2) mainly is to estimate the relationship between change in returns at time $t\left(\Delta X_{t}\right)$ and returns at time $\mathrm{t}-1\left(\mathrm{X}_{\mathrm{t}-1}\right)$. The null hypothesis $\left(\mathrm{H}_{0}\right)$ is that there is a unit root (or $\left.\delta=0\right)$. In that case, no relationship is found out, the variables are non-stationary and the market is weak-form efficient. By contrast, the alternative hypothesis $\left(\mathrm{H}_{1}\right)$ is that there is not a unit root $($ or $\delta \neq 0)$. That means there is a positive or negative relationship, the variables are stationary and the index is predictable.

To test the value of the slope $(\delta)$, this study refers the $\tau$-statistic, which is calculated in the same way as a student's t-statistic, in order to provide critical region. This research uses the table of Response Surface Estimates of Critical Values (These relate the 1\%,5\% and 10\% lower-tail critical values for the test statistics discussed above, for various values of $\mathrm{N}$, to the sample size $\mathrm{T}$ ) provided by MacKinnon 2010. If the absolute value of $\tau$ is smaller than the absolute value of critical values, we cannot reject the null hypothesis, so unit root is present; or the log returns are non-stationary. In other word, we cannot predict returns based on past returns because their statistical properties are not constant.

\subsubsection{Auto-Correlation Test}

In auto-correlation test, if the serial correlation coefficients between returns at time $t\left(\mathrm{X}_{\mathrm{t}}\right)$ and returns at time $\mathrm{t}-\mathrm{k}\left(\mathrm{X}_{\mathrm{t}-\mathrm{k}}\right)$ are significantly deviate from zero, the stock prices is dependent and predictable. Therefore, there is possibility for profitable trading. The serial correlation coefficient is defined as: 


$$
\rho_{k}=\frac{\sum_{t=1}^{T-k}\left(r_{t}-\bar{r}\right)\left(r_{t-k}-\bar{r}\right)}{\sum_{t=1}^{T}\left(r_{t}-\bar{r}\right)^{2}}
$$

where $\rho_{\mathrm{k}}$ is the serial correlation coefficient of lag $\mathrm{k}, \mathrm{T}$ is the sample size, $\mathrm{k}$ is the lag length, $\mathrm{r}_{\mathrm{t}}$ is the stock return at time $t$, and $\bar{r}$ is the sample mean of the stock returns.

The statistical test of autocorrelation was first introduced by Box and Pierce (1970); however, there was difficulty due to its approximations. By solving this issue, Ljung and Box (1978) modified the Q-statistics, which was recommended to be used in practical studies. This is the joint hypothesis test that all correlations are together equal to zero or not. The test statistics is:

$$
Q=T(T+2) \sum_{k=1}^{m} \frac{\rho_{k}^{2}}{T-k}
$$

where $\mathrm{T}$ is the sample size, $\mathrm{k}$ is the lag length, $\mathrm{m}$ is the maximum number of lags being tested, $\rho_{\mathrm{k}}$ is the serial correlation coefficient of lag $\mathrm{k}$.

The Chi-squared distribution (These relate the $1 \%, 5 \%$ and $10 \%$ critical values for the test statistics discussed above, for various values of $\mathrm{N}$, to the sample size $\mathrm{T}$ ) is used to compare to the Q-statistics. If the value of Q-statistics is smaller or equals to the critical value, we cannot reject the null hypothesis $\left(H_{0}\right): \rho_{1}=\rho_{2}=\rho_{3}=\ldots=\rho_{k}=0$. In that case, the first $\mathrm{k}$ autocorrelations are zero. On the other hand, the alternative hypothesis $\left(\mathrm{H}_{1}\right)$ is that $\rho_{\mathrm{j}}$ is different from zero for some $\mathrm{j}$. This means the stock returns exhibit serial correlation.

\subsubsection{Runs Test}

In empirical research of the EMH, a run is defined as a sequence of consecutive stock returns which are higher/smaller than the mean. If a series of data is random, the observed number of runs in the series should be close to the expected number of runs.

The null hypothesis $\left(\mathrm{H}_{0}\right)$ of runs test is that the stock prices are in a random manner with independent price changes. Therefore, the market is weak-form efficient. The alternative hypothesis $\left(\mathrm{H}_{1}\right)$ is that the stock prices are not in a random manner. Runs tests adopt the Z-statistic:

$$
Z=\frac{R-\bar{R}}{\sigma_{R}}
$$

where $\mathrm{R}$ is the total number of runs; $\bar{R}$ is the expected number of runs calculated as following:

$$
\bar{R}=\frac{2 N_{+} N_{-}}{N}+1
$$

$\mathrm{N}_{+}$is the number of positive runs and $\mathrm{N}_{-}$is the number of negative runs. And:

$$
\sigma_{R}^{2}=\frac{2 N_{+} N_{-}\left(2 N_{+} N_{-}-N\right)}{N^{2}(N-1)}
$$

The Z-statistic can be used in this test because it is approximately normal distributed for large sample size; and it is to examine the difference between the total number and expected number of runs. The run tests used is two-tail tests. If the absolute value of $\mathrm{Z}$ is higher than the absolute value of critical value $\left(\mathrm{Z}_{1-\alpha / 2}\right)$, we reject the null hypothesis. In this case, we do not have evidences supporting for the weak form of efficiency in the Vietnamese stock market.

\subsubsection{Variance Ratio Test}

Variance ratio test is the next test employed to examine the weak-form efficiency in practice. The use of the variance ratio test is based on the idea that price movements follow a random walk. The model investigated, which was introduced by Lo and MacKinlay (1988), in this test is that:

$$
\mathrm{X}_{\mathrm{t}}=\mu+\mathrm{X}_{\mathrm{t}-1}+\varepsilon_{\mathrm{t}}
$$

where $X_{t}$ is the stock prices at time $t, \mu$ is parameter and $\varepsilon_{t}$ is the random disturbance term.

The idea of this test is that: with the sample size of $n q+1$, the variance ratio of q-period returns is as following:

$$
V(q)=\frac{\operatorname{Var}\left(X_{t}-X_{t-q}\right) / q}{\operatorname{Var}\left(X_{t}-X_{t-1}\right)}
$$


According to the random walk hypothesis, $\mathrm{V}(\mathrm{q})$ should be a particular linear combination of the first (q-1) autocorrelation coefficients. In other words, $\mathrm{V}(\mathrm{q})$ is equal to 1 for all horizons q. On the other hand, $\mathrm{V}(\mathrm{q})$ is higher (lower) than unity if returns are positively (or negatively) auto-correlated. In the variance ratio, the statistic is generated based on the estimator $\mathrm{V}(\mathrm{q})$ as following:

$$
V R(q)=\frac{\widehat{\sigma}^{2}(q)}{\widehat{\sigma}^{2}(1)}
$$

where $\hat{\sigma}^{2}(1)$ is the variance of one-period return; and $\hat{\sigma}^{2}(q)$ is the unbiased estimator of the q-period return variance.

$$
\begin{gathered}
\hat{\sigma}^{2}(1)=\frac{1}{n q-1} \sum_{t=1}^{n q}\left(X_{t}-X_{t-1}-\hat{\mu}\right)^{2} \\
\hat{\sigma}^{2}(q)=\frac{1}{m} \sum_{t=1}^{n q}\left(X_{t}-X_{t-q}-q \hat{\mu}\right)^{2} \\
m=q(n q-q+1)\left(1-\frac{q}{n q}\right)
\end{gathered}
$$

$\hat{\mu}$ is the estimated mean $\hat{\mu}=\frac{1}{n q} \sum_{t=1}^{n q}\left(X_{t}-X_{t-1}\right)$

The null hypothesis $\left(\mathrm{H}_{0}\right)$ is that $\operatorname{VR}(\mathrm{q})$ is equal to 1 . In this case, no autocorrelation in return series. Alternatively, the hypothesis $\left(\mathrm{H}_{1}\right)$ is that $\mathrm{VR}(\mathrm{q})$ is drift further from 1 for some horizons $\mathrm{q}$. The M-statistics, which was introduced by Lo and MacKinlay (1988) to test the null hypothesis, is:

$$
M(q)=\frac{V R(x ; q)-1}{\emptyset(q)^{1 / 2}}
$$

Under the homoscedastic hypothesis:

$$
\varnothing(q)=\frac{2(2 q-1)(q-1)}{3 q(n q)}
$$

Under the heteroskedastic hypothesis

$$
\begin{gathered}
\emptyset^{*}(q)=\sum_{j=1}^{q-1}\left[\frac{2(q-j)}{q}\right]^{2} \delta(j) \\
\delta(j)=\frac{\sum_{t=j+1}^{n q}\left(X_{t}-X_{t-1}-\widehat{\mu}\right)^{2}\left(X_{t-j}-X_{t-j-1}-\widehat{\mu}\right)^{2}}{\left[\sum_{t=1}^{n q}\left(X_{t}-X_{t-1}-\widehat{\mu}\right)^{2}\right]^{2}}
\end{gathered}
$$

The critical region for the test follows the rule for standard normal distribution. If the absolute value of $\mathrm{M}$ is higher than the absolute value of critical value at the $\alpha / 2$ significant level, we reject the null hypothesis. As consequence, the stock market is not efficient in the weak form. On the other hand, there is no evidence to reject the weak-form efficiency in the stock market if the value of $\mathrm{M}$ is smaller or equal to the critical value.

\section{Empirical Results and Discussion}

\subsection{Division of Period}

The study attempts to split the period from 2000:07 to 2019:06 to assess the return predictability on the Vietnamese stock market in different levels of market volatility. Splitting period has an important role in analysing the return predictability on this market because it helps the study show the forecast power in typical contexts. Standard deviation of VN-Index returns are employed to measure volatility of the stock market. 


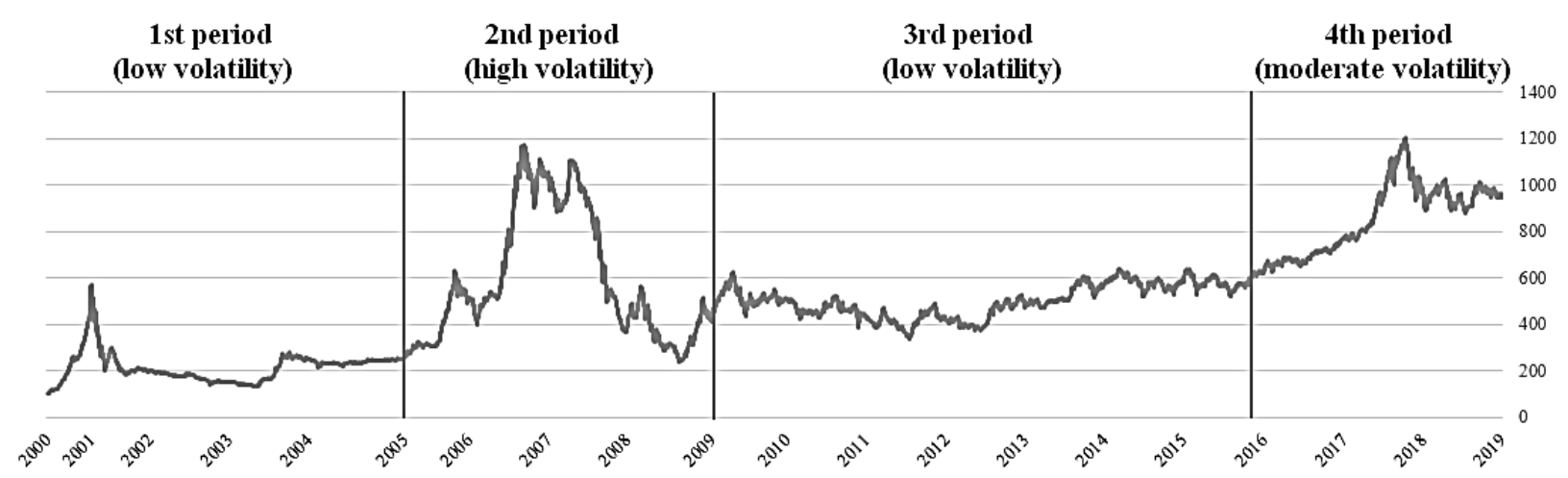

Figure 3. Daily VN-Index and period splitting

Table 1. Splitting samples of the VN-Index

\begin{tabular}{llll}
\hline Sample & Period & $\begin{array}{l}\text { Standard deviation } \\
\text { of stock price }\end{array}$ & $\begin{array}{l}\text { The number } \\
\text { observations }\end{array}$ \\
\hline Full sample & $28 / 07 / 2000-28 / 06 / 2019$ & 256.68 & 4556 \\
\hline Subsample 1 (1st period) & $28 / 07 / 2000-09 / 09 / 2005$ & 63.12 & 1118 \\
\hline Subsample 2 (2nd period) & $12 / 09 / 2005-23 / 07 / 2009$ & 275.60 & 963 \\
\hline Subsample 3 (3rd period) & $24 / 07 / 2009-21 / 04 / 2016$ & 69.56 & 1680 \\
\hline Subsample 4 (4th period) & $22 / 04 / 2016-28 / 06 / 2019$ & 155.27 & 795 \\
\hline
\end{tabular}

As can be seen from Figure 3 and Table 1, based on the standard deviation of the daily VN-Index, there are four periods with different stock volatility on the Vietnamese stock market. The first stock market period is from 28 th July 2000 to 09th September 2005. During this period, the index was quite stable except for a surge in 2001; however, the market was back to the starting point in 2002 and kept quite steady for the remaining time. The standard deviation of this period is at lowest level of 63.12. The second period (from 12th September 2005 to 23 th July 2009) is the most fluctuating time with the standard deviation of 275.60. The third period is another stable period with the standard deviation of 69.56. The fourth period of the stock market is from 22nd April 2016 to 28 th June 2019. The standard deviation of this time is at moderate level of 155.27.

\subsection{Data Analysis}

\subsubsection{Data Description}

Before analysing data, this part is to provide an overview about description statistics of daily returns of the VN-Index. Data is collected from Vndirect Securities Corp.'s website. The full sample is divided into four sub-periods.

Table 2. Description statistics for the daily returns of the VN-Index

\begin{tabular}{|c|c|c|c|c|c|c|c|}
\hline \multirow{3}{*}{ Statistics } & \multicolumn{7}{|l|}{ Time series } \\
\hline & Full period & $1^{\text {st }}$ period & $2^{\text {nd }}$ period & $3^{\text {rd }}$ period & & $4^{\text {th }}$ period & \\
\hline & $\begin{array}{l}\text { 2000:07 } \\
\text { 2019:06 }\end{array}$ & $\begin{array}{ll} & \text { 2000:07 } \\
\text { 2005:09 }\end{array}$ & $\begin{array}{l}\text { 2005:09 } \\
\text { 2009:07 }\end{array}$ & $\begin{array}{l}\text { 2009:07 } \\
\text { 2016:04 }\end{array}$ & - & $\begin{array}{l}\text { 2016:04 } \\
\text { 2019:06 }\end{array}$ & - \\
\hline Observation & 4556 & 1118 & 963 & 1680 & & 795 & \\
\hline Mean & 0.049 & 0.082 & 0.053 & 0.017 & & 0.063 & \\
\hline Median & 0.040 & -0.008 & 0.008 & 0.061 & & 0.136 & \\
\hline Maximum & 7.741 & 6.656 & 7.741 & 4.615 & & 3.701 & \\
\hline Minimum & -7.656 & -7.656 & -4.971 & -6.051 & & -5.232 & \\
\hline
\end{tabular}




\begin{tabular}{llllll}
\hline Standard deviation & 0.01504 & 0.01579 & 0.02056 & 0.01260 & 0.00991 \\
\hline Skewness & -0.25665 & -0.53081 & 0.01151 & -0.37742 & -0.75686 \\
\hline Kurtosis & 6.16946 & 9.91437 & 2.94745 & 4.56495 & 6.64990 \\
\hline Jarque-Bera & 1956.944 & 517.1861 & 0.13203 & 211.3178 & 517.1861 \\
\hline
\end{tabular}

Table 2 represents the description statistics for the daily returns of the VN-Index in the full period and four sub-periods. The mean, median, maximum and minimum are in percentage. As can be seen from Table 2, the Vietnamese stock market has positive mean returns. The standard deviation of returns in the second period is the largest compared to the others. This indicates that this period is the riskiest time throughout the time studied. Interestingly, although the daily VN-Index in the fourth period experienced a moderate volatility, the returns in this period has the lowest standard deviation of about 0.099 . The first and the second periods were quite risky with the standard deviation of 0.016 and 0.013 , respectively.

Skewness, Kurtosis and Jarque-Bera statistics describe the distribution of the daily returns. The Skewness values are negative except for the second sub-period, indicating that the mass of the distribution is on the right side of the mean. The distributions of returns on the first and the fourth periods also have high peaks with the Kurtosis values of 9.91 and 6.65 , respectively, representing strongly centred of the distribution. In contrast, the third and the fourth sub-samples witness a left-tailed distribution with lower peaks. In addition, the statistics also show that full sample and sub-samples are not normally distributed, except for the second sub-sample (Figure 4).

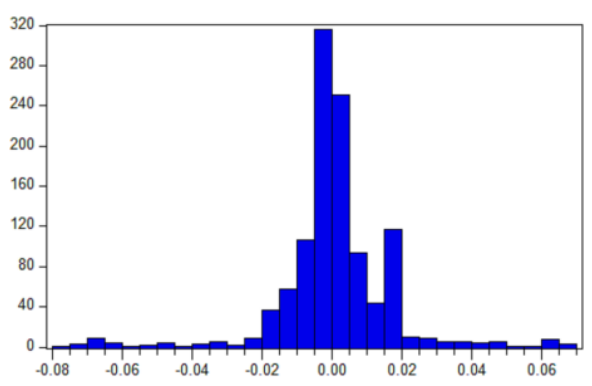

The first period (Low volatility)

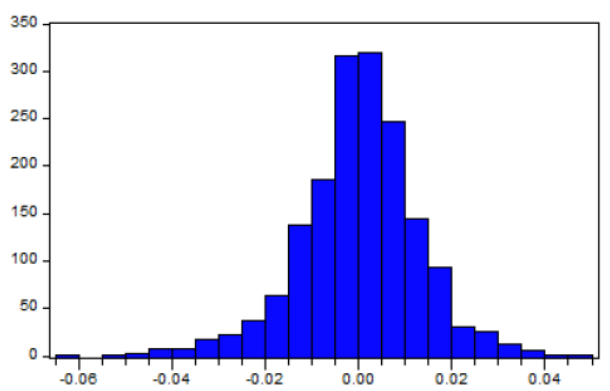

The third period (Low volatility)

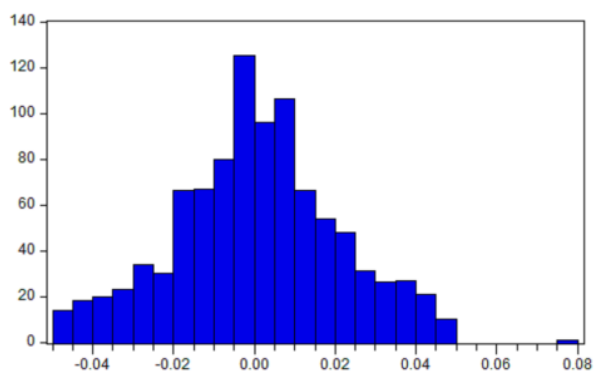

The second period (High volatility)

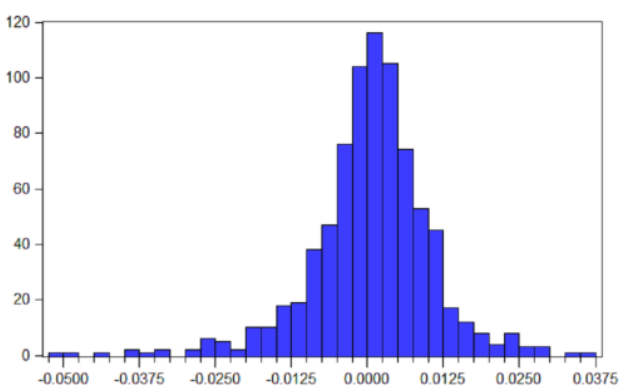

The fourth period (Moderate volatility)

Figure 4. Histogram of daily returns of the VN-Index

\subsubsection{Unit Root Test}

Based on the framework introduced by Dickey and Fuller (1979) and MacKinnon (1990), the liner regression in Equation (2) is run in order to show the autocorrelation at the first lag of stock returns. The following table shows the results of this model, in which $\mathrm{t}(\delta)$ is the test statistic of the Unit root test. 
Table 3. Regressions for the unit root test for daily returns of the VN-Index (Note 1)

\begin{tabular}{|c|c|c|c|c|c|}
\hline \multirow{3}{*}{ Sample } & \multicolumn{5}{|c|}{ Result of regression } \\
\hline & \multicolumn{3}{|c|}{$\Delta X_{t}=\mu+\beta t+\delta X_{t-1}+\sum_{i=1}^{N} \varphi_{i} \Delta X_{t-i}+e_{i}$} & \multicolumn{2}{|l|}{ (2) } \\
\hline & $\mu$ & $\boldsymbol{\beta}$ & $\delta$ & $t(\delta)$ & $\varphi_{1}$ \\
\hline Full sample & 0.0000 & 0.0000 & -0.7446 & -41.6724 & 0.0236 \\
\hline $1^{\text {st }}$ period & -0.0003 & 0.0000 & -0.6364 & -20.1019 & 0.1213 \\
\hline $2^{\text {nd }}$ period & -0.0130 & 0.0000 & -0.7639 & -19.7496 & 0.0650 \\
\hline $3^{\text {rd }}$ period & 0.0002 & 0.0000 & -0.8320 & -26.3104 & -0.0120 \\
\hline $4^{\text {th }}$ period & -0.0003 & 0.0000 & -0.8899 & -17.8745 & -0.1024 \\
\hline \multirow{3}{*}{ Test critical values at $\alpha$ level } & & & $1 \%$ level & -3.9638 & \\
\hline & & & $5 \%$ level & -3.4126 & \\
\hline & & & $10 \%$ level & -3.1279 & \\
\hline
\end{tabular}

As can be seen from Table 3, all t-statistics have absolute values higher than the absolute values of test critical values at all $1 \%, 5 \%$ and $10 \%$ levels. In other words, we reject the null hypothesis of unit root in all periods studied. This indicates that the returns variable is stationary and they are integrated of order one. Therefore, there is evidence that the returns at time $t\left(\Delta X_{t}\right)$ can be predicted from the returns at one period difference $\left(\Delta X_{t-1}\right)$ regardless of the level of volatility of the market. Mechanical trading strategies are considered to be useful in the Vietnamese stock market.

4.2.3 Auto-Correlation Test

Table 4. Results of Auto-correlation tests for daily returns of VN-Index (Note 2)

\begin{tabular}{|c|c|c|c|c|c|c|c|c|c|c|}
\hline \multirow{3}{*}{ Lag } & \multicolumn{2}{|c|}{ Full period } & \multicolumn{2}{|c|}{$\mathbf{1}^{\text {st }}$ period } & \multicolumn{2}{|c|}{$2^{\text {nd }}$ period } & \multicolumn{2}{|c|}{$3^{\text {rd }}$ period } & \multicolumn{2}{|c|}{$4^{\text {th }}$ period } \\
\hline & $\begin{array}{l}\text { 2000:0 } \\
\text { 2019:0 }\end{array}$ & & $\begin{array}{l}2000: 07 \\
2005: 09\end{array}$ & & $\begin{array}{l}\text { 2005: } \\
\text { 2009: }\end{array}$ & & $\begin{array}{l}\text { 2009:07 } \\
\text { 2016:04 }\end{array}$ & - & 2016:0 & 2019:06 \\
\hline & AC & Q-stat & $\mathbf{A C}$ & Q-stat & $\mathbf{A C}$ & Q-stat & $\mathbf{A C}$ & Q-stat & $\mathbf{A C}$ & Q-stat \\
\hline 1 & 0.272 & 338.53 & 0.433 & 210.16 & 0.287 & 79.446 & 0.153 & 39.209 & 0.007 & 0.0382 \\
\hline 2 & 0.052 & 350.99 & 0.089 & 219.04 & 0.027 & 80.126 & 0.031 & 40.872 & 0.105 & 8.8642 \\
\hline 3 & 0.019 & 352.69 & 0.01 & 219.16 & 0.029 & 80.927 & 0.005 & 40.918 & 0.05 & 10.869 \\
\hline 4 & 0.086 & 386.56 & 0.099 & 230.24 & 0.137 & 99.118 & 0.008 & 41.03 & 0.062 & 13.962 \\
\hline 5 & 0.098 & 430.29 & 0.179 & 266.23 & 0.128 & 115.04 & 0.018 & 41.563 & -0.045 & 15.604 \\
\hline 6 & 0.077 & 457.37 & 0.224 & 322.96 & 0.054 & 117.84 & -0.024 & 42.525 & -0.012 & 15.714 \\
\hline 7 & 0.045 & 466.45 & 0.100 & 334.2 & 0.018 & 118.16 & 0.039 & 45.112 & -0.03 & 16.437 \\
\hline 8 & 0.026 & 469.57 & 0.053 & 337.38 & 0.028 & 118.91 & 0.000 & 45.112 & -0.014 & 16.601 \\
\hline 9 & 0.018 & 471.1 & 0.105 & 349.76 & 0.016 & 119.15 & -0.029 & 46.572 & -0.086 & 22.627 \\
\hline 10 & 0.033 & 475.93 & 0.127 & 367.86 & 0.000 & 119.15 & -0.005 & 46.617 & 0.013 & 22.768 \\
\hline 11 & 0.045 & 485.16 & 0.132 & 387.57 & 0.025 & 119.77 & -0.002 & 46.625 & 0.000 & 22.768 \\
\hline 12 & 0.023 & 487.55 & -0.001 & 387.57 & 0.082 & 126.28 & -0.048 & 50.588 & 0.016 & 22.965 \\
\hline
\end{tabular}

Table 5. Critical values of the Chi-squared distribution (Note 3)

\begin{tabular}{lccc}
\hline $\mathbf{d f}$ & $\chi^{2}{ }_{\mathbf{0 . 0 1 0}}$ & $\chi^{2}{ }_{\mathbf{0 . 0 5 0}}$ & $\chi^{2}{ }_{\mathbf{0 . 1 0 0}}$ \\
\hline $\mathbf{1}$ & 6.635 & 3.841 & 2.706 \\
\hline
\end{tabular}




\begin{tabular}{llll}
\hline $\mathbf{2}$ & 9.210 & 5.991 & 4.605 \\
\hline $\mathbf{3}$ & 11.345 & 7.815 & 6.251 \\
\hline $\mathbf{4}$ & 13.277 & 9.488 & 7.779 \\
\hline $\mathbf{5}$ & 15.086 & 11.070 & 9.236 \\
\hline $\mathbf{6}$ & 16.812 & 12.592 & 10.645 \\
\hline $\mathbf{7}$ & 18.475 & 14.067 & 12.017 \\
\hline $\mathbf{8}$ & 20.090 & 15.507 & 13.362 \\
\hline $\mathbf{9}$ & 21.666 & 16.919 & 14.684 \\
\hline $\mathbf{1 0}$ & 23.209 & 18.307 & 15.987 \\
\hline $\mathbf{1 1}$ & 24.725 & 19.675 & 17.275 \\
\hline $\mathbf{1 2}$ & 26.217 & 21.026 & 18.549 \\
\hline
\end{tabular}

Firstly, Table 4 also shows that the auto-correlations are positive in almost all of the periods studied except for the fourth period, indicating a tendency to form a trend in the price movement. An increase in the VN-Index can be followed by a growth in subsequent days, and vice versa. However, the coefficient of the returns declined over 19 years studied and the fourth period experienced the lowest numbers compared to other periods. Moreover, the auto-correlations in the fourth period are also negative at several period differences such as the 7th, 8th and 9th lag. This proves that the relationship between the daily VN-Index and itself over time is weaken in recent years.

This above trend is also proved by examining the Q-statistics. At the same lag, the statistic for the fourth period is the smallest number compared to those for other periods. For example, at the 1st lag, the Q-statistic of for the fourth period is 0.0382 , which is the smallest number among the statistics for the first-order autocorrelation. This illustrates that the extent of rejection is less pronounced throughout the period studied, or the improvement of market efficiency.

Another finding is that the level of volatility did not affect the degrees of conformity to the market efficiency. By comparing Q-statistics in Table 4 and critical values in Table 5, it can be seen that for all series studied except for the four sub-sample, the Q-statistics reject the null hypothesis that the autocorrelations are jointly zero at all lags.

4.2.4 Runs Test

Table 6. Results of Runs test for the daily returns of the VN-Index (Note 4)

\begin{tabular}{llllll}
\hline \multirow{2}{*}{ Variable } & Full sample & $\mathbf{1}^{\text {st }}$ period & $\mathbf{2}^{\text {nd }}$ period & $\mathbf{3}^{\text {rd }}$ period & $\mathbf{4}^{\text {th }}$ period \\
\cline { 2 - 6 } & $\mathbf{2 0 0 0 : 0 7}$ & $-2000: 07$ & $-2005: 09$ & $-2009: 07$ & $-2016: 04$ \\
& $\mathbf{2 0 1 9 : 0 6}$ & $\mathbf{2 0 0 5 : 0 9}$ & $\mathbf{2 0 0 9 : 0 7}$ & $\mathbf{2 0 1 6 : 0 4}$ & $\mathbf{2 0 1 9 : 0 6}$ \\
\hline Observation $(\mathbf{N})$ & 4556 & 1118 & 963 & 1680 & 795 \\
\hline Total number of runs $(\mathbf{R})$ & 1901 & 358 & 365 & 781 & 383 \\
\hline Expected number of runs $(\overline{\boldsymbol{R}})$ & 2279 & 554 & 482 & 840 & 397 \\
\hline Observations above mean & 2258 & 502 & 466 & 867 & 421 \\
\hline Observations below mean & 2298 & 616 & 497 & 813 & 374 \\
\hline Z-statistic & -11.1971 & -11.8637 & -7.5524 & -2.8892 & -1.0051 \\
\hline Test critical value $(\boldsymbol{\alpha}$ significant level) & & & & \\
\hline $\boldsymbol{d f}$ & $\mathbf{1 9 0 1}$ & $\mathbf{3 5 8}$ & $\mathbf{3 6 5}$ & $\mathbf{7 8 1}$ & $\mathbf{3 8 3}$ \\
\hline $\mathbf{1 \%}$ level & 2.576 & 2.586 & 2.586 & 2.581 & 2.586 \\
\hline $\mathbf{5 \%}$ level & 1.960 & 1.965 & 1.965 & 1.962 & 1.965 \\
\hline $\mathbf{1 0 \%}$ level & 1.645 & 1.648 & 1.648 & 1.646 & 1.648 \\
\hline
\end{tabular}


Firstly, in terms of the difference between the total number and the expected number of runs, the gap is the most significant in the first period, which has the lowest stock volatility. On the other hand, the gap is the smallest in the fourth period, which has the moderate stock volatility. Therefore, there is evidence that the level of volatility in the Vietnamese market did not affect its efficiency.

Secondly, in terms of Z-statistics, the absolute value of Z-statistic tended to decrease over time. In the first and the second period, the null hypothesis that the VN-Index follows a random walk was strongly rejected at all significant level. However, the results cannot reject the independence among stock returns in the third and fourth period at 5 and 10 percent significant level. This result indicates that the market efficiency has improved throughout the period studied. This result is consistent with the result of Q-statistics from the autocorrelation test.

\subsubsection{Variance Ratio Test}

The null hypothesis $\left(\mathrm{H}_{0}\right)$ is that the VN-Index follows a random walk if M-statistics are greater than the critical values. In this case, the variance ratio between q-period return variance and one-period return variance is 1 . Alternatively, there is no evidence of random walk in the stock market. In this study, the intervals (q) are chosen randomly as $2,4,8,16$ and 32 . Table 7 shows the results of the variance ratio tests for the full period and three sub-periods.

Table 7. Results of variance ratio tests of daily VN-Index (Note 5)

\begin{tabular}{|c|c|c|c|c|c|}
\hline \multirow{2}{*}{$\mathbf{q}$} & \multicolumn{5}{|l|}{ Variable } \\
\hline & Observation & Variance & Var. ratio & M-stat & $\mathbf{M}^{*}$-stat \\
\hline \multicolumn{6}{|c|}{ Full period (2000:07 - 2019:06) } \\
\hline 2 & 4557 & 84.9418 & 1.2003 & 13.5260 & 6.5688 \\
\hline 4 & 4555 & 94.3075 & 1.3327 & 12.0061 & 5.9632 \\
\hline 8 & 4551 & 110.5690 & 1.5625 & 12.8381 & 6.5425 \\
\hline 16 & 4543 & 126.7930 & 1.7918 & 12.1440 & 6.3436 \\
\hline 32 & 4527 & 156.0860 & 2.2057 & 12.7615 & 6.8465 \\
\hline \multicolumn{6}{|c|}{ 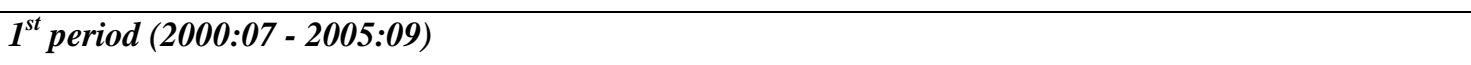 } \\
\hline 2 & 1116 & 36.8169 & 1.4515 & 15.0886 & 3.6957 \\
\hline 4 & 1114 & 44.1805 & 1.7418 & 13.2514 & 3.4031 \\
\hline 8 & 1110 & 53.8158 & 2.1216 & 12.6728 & 3.2986 \\
\hline 16 & 1102 & 69.8113 & 2.7522 & 13.3045 & 3.5285 \\
\hline 32 & 1086 & 90.4887 & 3.5674 & 13.4522 & 3.7431 \\
\hline \multicolumn{6}{|c|}{$2^{\text {nd }}$ period (2005:09 - 2009:07) } \\
\hline 2 & 961 & 209.8230 & 1.2650 & 8.2179 & 5.4008 \\
\hline 4 & 959 & 227.3980 & 1.3709 & 6.1493 & 4.1526 \\
\hline 8 & 955 & 280.8620 & 1.6932 & 7.2688 & 5.0364 \\
\hline 16 & 947 & 348.3490 & 2.1001 & 7.7516 & 5.4841 \\
\hline 32 & 931 & 478.4170 & 2.8842 & 9.1620 & 6.5905 \\
\hline \multicolumn{6}{|c|}{$3^{\text {rd }}$ period (2009:07 - 2016:04) } \\
\hline 2 & 1678 & 44.1568 & 1.1416 & 5.8011 & 4.4414 \\
\hline 4 & 1676 & 48.4120 & 1.2516 & 5.5103 & 4.0885 \\
\hline 8 & 1672 & 51.3620 & 1.3279 & 4.5414 & 3.4120 \\
\hline 16 & 1664 & 50.9444 & 1.3171 & 2.9515 & 2.3111 \\
\hline 32 & 1648 & 47.1123 & 1.2180 & 1.4003 & 1.1419 \\
\hline
\end{tabular}




\begin{tabular}{llllll}
\hline \multicolumn{4}{l}{$\mathbf{4}^{\text {th }}$ period (2016:04 - 2019:06) } & & \\
\hline $\mathbf{2}$ & 793 & 87.0405 & 0.9992 & -0.0218 & -0.0122 \\
\hline $\mathbf{4}$ & 791 & 101.0130 & 1.1596 & 2.4044 & 1.3507 \\
\hline $\mathbf{8}$ & 787 & 113.9050 & 1.3076 & 2.9305 & 1.7057 \\
\hline $\mathbf{1 6}$ & 779 & 110.7610 & 1.2715 & 1.7383 & 1.0498 \\
\hline $\mathbf{3 2}$ & 763 & 122.0460 & 1.4011 & 1.7718 & 1.1189 \\
\hline
\end{tabular}

Table 7 shows that the variance ratio varies depending on the period studied. Firstly, at the same lag, the fourth period, which has moderate stock volatility, has the variance ratios which are closest to 1 compared the other three periods. The variance ratios nearly 1 indicates the existence of the random walk hypothesis in this period. On the other hand, both the period with low stock volatility and the period with high volatility tends to have the variance ratio drifting from 1 . For example, the first period with the lowest degrees of volatility has the number ranging from which are 1.4515 to 2.7522 . The second period, which has high degree of volatility, has the variance ratio ranging from 1.2650 to 2.8842 . The third period with the low degree of volatility has the variance ratio ranging from 1.1416 to 1.3279 (Table 7). This trend indicates that the degree of stock volatility does not influence the existence of the random walk hypothesis.

By comparing $\mathrm{M}$-statistics and $\mathrm{M}^{*}$-statistics from Table 7 and the critical values, the variance ratio tests reveals two different results. On the one hand, for the full period, the first, the second and the third sub-periods, statistics strongly reject the null hypothesis of random walk in all intervals under both homoscedastic and heteroskedastic assumptions. In this case, the variance ratio tests reject the weak-form efficiency in the Vietnamese market. On the other hand, for the fourth sub-sample, there is not sufficient evidence to reject the null hypothesis of heteroscedasticity at 1 percent level of significance. In other words, for the fourth period, the random walk hypothesis cannot be rejected in the moderate volatile market in heteroscedastic assumptions. In addition, for the fourth period, the rejection of weak-form efficiency is also less pronounced than other sub-periods because the test statistics is less than the critical values at all lags. Therefore, there is evidence for the improvement of random walk in the market. This result is consistent with findings from analysing variance ratios.

\subsection{Discussion}

The first period is from July 2000 to September 2005. This period has the lowest degree of stock market volatility. Q-statistics of the auto-correlation test, Z- statistics of the runs test, $\mathrm{M}$-statistics and $\mathrm{M}^{*}$-statistic of the variance ratio test provide the strongest rejection compared to the other periods. In short, in the early stage of operations, when the VN-Index is quite stable, there is possibility to predict the future prices based on the past and current returns. Thus, investors have potentials to gain abnormal returns in high stock market volatility.

The second period is from September 2005 to July 2009. In this time, the VN-Index is the most fluctuating. All tests employed reject the null hypothesis of the weak-form efficiency in this period. That means the market in the second period is not consistent with the weak-form efficiency. However, the rejection of random walk hypothesis for this high volatile period is not as strong as the first period.

The third period is from July 2009 to April 2016. Together with the first period, this period has a low degree of stock market volatility. The unit root test strongly rejects the random walk hypothesis in this period. However, in the run test and auto-correlation test, the third period witnessed a weaker rejection compared to the two first sub-period due to lower Q-statistics and Z-statistics. The result from variance ratio, however, supports the weak-form efficiency of the Vietnamese stock market at 1 percent significant level at the lag 32. This illustrates that during this period, the market was more efficient than before; and the future prices cannot be predicted by observing the past and current prices.

The fourth period is from April 2016 to June 2019. This is the most recent period with moderate stock market volatility. In the last period, although the unit root test indicates that the Vietnamese market does not follow a random walk, auto-correlation, run test and variance ratio test show that the null hypothesis cannot be rejected. This means the market has experienced a considerable improvement in efficiency over time. It can be explained by the changes in regulations and investor confidence. 


\section{Conclusion and Recommendation}

\subsection{Conclusion}

There are three main points is concluded about the Vietnamese stock market.

Firstly, the Vietnamese stock market is not efficient in weak form. In general, all tests for the full period between 2000:07 and 2019:06 illustrate that the daily VN-Index does not follow a random walk. This finding is consistent with the results of researches by Claessens et al. (1995) and Chaudhuri and $\mathrm{Wu}$ (2003) in developing countries. Under both under both homoscedastic and heteroscedastic assumptions, despite several evidences supporting the efficiency in some periods, in general, there is positive relationship between past returns and future returns.

Secondly, the efficiency of the Vietnamese stock market is not affected by the condition of stock volatility. The 2000:07 - 2005:09 period (the first period) is the time with the lowest degree of stock volatility. However, this period experiences the strongest rejection of the random walk hypothesis. On the other hand, results from run tests and variance ratio tests for the 2016:04 - 2019:06 period (the fourth period), which experienced a moderate stock volatily, cannot reject the random walk hypothesis. Moreover, the rejection of the null hypothesis for the most fluctuating time (the second period) is less pronounced than the low time (the third period). Therefore, the forecast power of past returns does not rely on degree of stock volatility. the finding of this study is different from the finding by LeRoy and Parke (1992). They found out the rejection of efficient market when the stock markets exhibit 'excess stock volatility'.

Thirdly, there is an improvement in the market efficiency in recent years. The fourth period consists of the most recent data from April 2016 to June 2019. Despite the moderate level of stock volatility, the rejection of the random walk hypothesis for this period is also weaker than the three previous periods. Q-statistics, Z-statistics, M-statistics and $\mathrm{M}^{*}$-statistics also proves the improvement in informational efficiency of the Vietnamese stock market over time. Phan and Zhou (2014) observed weekly data from 2000 to 2013 and also claimed that the market had become increasingly efficient. This finding is consistent with the findings of this study.

\subsection{Recommendation}

Behaviour of stock returns is crucial in making investment decisions of investors and financial decisions of financial managers. It influences the use of technical analysis and then affects the investment strategies.

Firstly, the Vietnamese stock market generally does not follow a random walk, so investors and financial managers can forecast the future prices based on the patterns of the past prices or other information. Auto-correlation test and variance ratio test indicate that any movement in prices can be followed by a change in the same direction. Therefore, investors and financial managers should implement a trend-following strategy to invest in the Vietnamese market. To implement this strategy, both technical analysis and fundamental analysis can be used to identify the fundamental values of securities and make decisions. For example, by observing stock prices during a period and doing research on companies' annual reports, traders should be in long position if he or she finds out that the stock is being traded below its fundamental value. The inefficiency of the Vietnamese stock market, so it provides many opportunities for enterprises and hardworking investors rather than unskilled investors.

Secondly, this study also proves that the behaviour of stock returns does not influence the return predictability on the Vietnamese stock market. Since the market is not weak-form efficient regardless of the degree of stock volatility, there is opportunity for financial managers to gain profits by "timing" security sales or share repurchases. For example, a firm has a plan for business expansion by buying stocks of a target company on the Vietnamese stock market. It is not necessary for its manager to concern about market volatility; technical analysis is one of useful techniques can be used to determine under-valued company.

Thirdly, on the other hand, the efficiency of the Vietnamese market has been improved recently, which is illustrated by the improvement in the fourth sub-period. As a result, investors who are used to making decisions based on technical analysis should change their strategy in investment. This is because technical analysis has gradually lost its effectiveness when the security prices start to "forget its memory". For instance, the improvement of market efficiency encourages investors to follow a passive investing strategy to minimise diversifiable risks. In this strategy, investors attempt to build a well-diversified portfolio based on the VN-Index. This is because when the stock market become increasingly efficient, it is difficult to go head of the market, so matching the index can be better than beating it.

In short, Vietnam has been one the most attractive countries for investment in Asia; and the stock market in Vietnam has been developing in both quantity and quality. The degree of conformity to the concept of market efficiency is 
various depending each time. Therefore, both existing and potential investors on the Vietnamese market should have different strategies in different periods.

\section{References}

Alexeev, V., \& Tapon, F. (2011). Testing weak form efficiency on the Toronto Stock Exchange. Journal of Empirical Finance, 18(4), 661-691. https://doi.org/10.1016/j.jempfin.2011.05.002

Alphonse, P., \& Nguyen, H. (2013). Momentum Effect: Evidence from the Vietnamese Stock Market. Macrothink Institute. Asian Journal of Finance \& Accounting, 5(2), 183-202. https://doi.org/10.5296/ajfa.v5i2.4310

Box, G. E. P., \& Pierce, D. A. (1970). Distribution of residual correlations in autoregressive-integrated moving average time series models. Journal of the American Statistical Association, 65(332), 1509-1526. https://doi.org/10.1080/01621459.1970.10481180

Buguk, C., \& Brorsen, B. (2003). Testing weak-form market efficiency: Evidence from the Istanbul stock exchange. International Review of Financial Analysis, 12, 579-590. https://doi.org/10.1016/S1057-5219(03)00065-6

Chaudhuri, K., \& Wu, Y. (2003). Random Walk Versus Breaking Trend in Stock Prices: Evidence from Emerging Markets. Journal of Banking and Finance, 27(4), 575-592. https://doi.org/10.1016/S0378-4266(01)00252-7

Claessens, S., Dasgupta, S., \& Glen, J. (1995). Return behavior in emerging stock markets. The World Bank Economic Review, 9(1), 131-151. https://doi.org/10.1093/wber/9.1.131

Do, N., Le, B., \& Nguyen, T. (2014). Stock-market efficiency in emerging markets: Evidence from Vietnamese Stock market. The 7th International Scientific Conference Finance and Performance of Firms in Science, Education and Practice (pp. 204-216).

Fama, E. (1965). The behaviour of stock-market prices. Journal of Business, 38(1), 34-105. https://doi.org/10.1086/294743

Fama, E. (1970). Efficient capital markets: A review of theory and empirical work. Journal of Finance, 25(2), 383-417. https://doi.org/10.2307/2325486

Fama, E. (1991). Efficient capital markets: II. The Journal of Finance, 46(5), 1575-1617. https://doi.org/10.1111/j.1540-6261.1991.tb04636.x

Fisher, L. (1966). Some new stock market indexes. Journal of Business, 39, 191-225. https://doi.org/10.1086/294848

Guidi, F., \& Gupta, R. (2011). Are ASEAN stock market efficient? Evidence from univariate and multivariate variance ratio tests. Griffith Business School. Discussion paper: Finance, No. 2011-13.

Konak, F., \& Şeker, Y. (2014). The Efficiency of Developed Markets: Empirical Evidence from FTSE 100. Journal of Advanced Management Science, 2(1), 29-32. https://doi.org/10.12720/joams.2.1.29-32

Leroy, S., \& Porter, R. (1981). The Present-Value Relation: Tests Based on Implied Variance Bounds. Econometrica, 49(3), 555-574. https://doi.org/10.2307/1911512

Ljung, G., \& Box, G. (1978). On a measure of lack of fit in time series models. Biometrika, 65(2), 297-303. https://doi.org/10.1093/biomet/65.2.297

Lo, A., \& MacKinlay, A. (1988). Stock Market Prices do not Follow Random Walks: Evidence from a Simple Specification Test. The Review of Financial Studies, 1(1), 41-66. https://doi.org/10.1093/rfs/1.1.41

Loc, T. (2006). Equitisation and stock-market development: the case of Vietnam. University of Groningen. Retrieved from http://www.rug.nl/research/portal/files/13151848/00_titlecon.pdf

MacKinnon, J. (1990). Critical Values for Cointegration Tests. Queen's Economics Department Working Paper, $1227,1-17$

Malkiel, B. (2003). The Efficient Market Hypothesis and Its Critics. Journal of Economic Perspectives, 17(1), 59-82. http://doi.org/10.1257/089533003321164958

Narayan, P., \& Smyth. (2006). Random Walk versus Multiple-Trend Breaks in Stock Prices: Evidence from Fifteen European Markets. Applied Financial Economics Letters, 2(1), 1-7. https://doi.org/10.1080/17446540500424784

Phan, K., \& Zhou, J. (2014). Market efficiency in emerging stock markets: A case study of the Vietnamese stock market. Journal of Business and Management, 16(4), 61-73. https://doi.org/10.9790/487X-16446173 
Saunders, M., Lewis, P., \& Thornhill, A. (2015). Research methods for business students (7th ed.). Pearson Education Limited.

Vietnamese Government. (2017). Socialist republic of Vietnam: Government Portal. Retrieved March 14, 2017, from http://vanban.chinhphu.vn/portal/page/portal/chinhphu/hethongvanban?class_id=1\&mode=detail\&document_id $=178433$

Vndirect. (2019). Overview. About Vndirect. Retrieved 21 August 2019, from https://invest.vndirect.com.vn/about-vndirect/

Vo, X., Nguyen, V., \& Pham, H. (2016). Financial structure and economic growth: The case of Vietnam. Eurasian Business Review, 6(2), 141-154. https://doi.org/10.1007/s40821-016-0042-8

World Bank. (2016). Vietnam. Retrieved March 9, 2007, from http://www.worldbank.org/en/country/vietnam/overview

\section{Notes}

Note 1. Table 3 represents estimation results for the regression of the Augmented Dickey-Fuller test. Equation (2) is explained in the Data sources and Methodology section. This is the regression with constant and time trend. Xt is stock returns at time t. Data collected is described in the Data sources and Methodology section. $\mathrm{t}(\delta)$ is the t-statistic for $\delta$.

Note 2. Table 4 represents estimation results for the auto-correlation tests for the observed daily-return data. Data collected is described in the Data sources and Methodology section. AC is the serial correlation coefficient, which represents the relationship between the time $t$ stock returns and the time $t-k$ stock return. AC is calculated by Equation (3). Q-stat is the Ljung-Box Q-statistics, which is calculated by Equation (4). "AC" stands for "Auto-correlation Coefficient". "Q-stat" stands for "Q-statistic".

Note 3. Table 5 represents the critical values of the Chi-squared distribution relating to the $1 \%, 5 \%$ and $10 \%$ significant level with the degree of freedom (df) from 1 to 12 . The range of $\mathrm{df}$ is between 1 and 12 aims to compare with the Q-statistics in Table 4.

Note 4. Table 6 represents the estimated results of the run tests for the daily returns of the VN-Index. Data collected is described in the Data Sources and Methodology section. Expected number of runs is calculated by Equation (6). Z-statistic is calculated by Equation (5). Test critical values is the critical region of normal distribution for two-tailed test with the degree of freedom (df) is the total number of runs. For example, at $\alpha$ significant level, critical area contains both the top $\alpha / 2$ of the distribution and the bottom $\alpha / 2$ of the distribution.

Note 5. Table 7 provides the results of variance ratio tests for the daily returns of the VN-Index. Variance calculated by Equation (8) represents the spread out of VN-Index at the qth lag. Variance ratio calculated by Equation (7) represents the ratio between Variance at the qth lag and the first lag. M-statistic, which is used for the test in homoscedastic assumptions, is calculated by Equation (9) and (10). $\mathbf{M}^{*}$-statistic, which is used for the test in heteroskedastic assumptions, is calculated by Equation (9) and (11). "q" is the number of period differences. "Var. ratio" represents "Variance ratio". "M-stat" represents "M-statistic". "M*-stat" represents "M*-statistic". 